Cahiers $d u$ MONDE RUSSE

\section{Cahiers du monde russe}

Russie - Empire russe - Union soviétique et États indépendants

45/3-4 | 2004

Varia

\title{
Jurij Aksjutin, Hruščevskaja « ottepel' » i obščestvennye nastroenija v SSSR v 1953-1964 gg.
}

\author{
Larissa Zakharova
}

\section{OpenEdition}

\section{Journals}

Édition électronique

URL : https://journals.openedition.org/monderusse/4207

DOI : $10.4000 /$ monderusse.4207

ISSN : $1777-5388$

Éditeur

Éditions de l'EHESS

\section{Édition imprimée}

Date de publication : 1 juillet 2004

Pagination : 713-715

ISBN : 2-7132-2009-2

ISSN : $1252-6576$

Référence électronique

Larissa Zakharova, "Jurij Aksjutin, Hruščevskaja « ottepel’ » i obščestvennye nastroenija v SSSR v 1953-1964 gg. », Cahiers du monde russe [En ligne], 45/3-4 | 2004, mis en ligne le 03 juin 2009, consulté le 03 septembre 2022. URL : http://journals.openedition.org/monderusse/4207 ; DOI : https://doi.org/10.4000/monderusse.4207

Ce document a été généré automatiquement le 3 septembre 2022

Tous droits réservés 


\title{
Jurij Aksjutin, Hruščevskaja " ottepel' » i obščestvennye nastroenija v SSSR v 1953-1964 gg.
}

\author{
Larissa Zakharova
}

\section{RÉFÉRENCE}

Jurij AKSJUTIN, Hruščevskaja " ottepel' » i obščestvennye nastroenija v SSSR v 1953-1964 gg. (Le « Dégel » khrouchtchévien et les états d'esprit dans l'opinion soviétique, 1953-1964). Moscou, ROSSPEN, 2004, 487 p.

1 Des enquêtes effectuées auprès des contemporains des événements politiques des années 1953-1964 constituent une des sources principales du travail de Jurij Aksjutin et font la nouveauté de ce genre d'ouvrage académique. Ainsi, 1500 anciens «simples citoyens soviétiques ", issus de différentes couches sociales et professionnelles, et interrogés en 1994-1999 par des étudiants de l'Université pédagogique de Moscou, s'expriment dans ce livre.

2 La structure de l'ouvrage consiste en une succession d'aperçus des moments cruciaux de l'histoire politique du Dégel, suivis de l'exposé des réactions de la population à ces faits. L'auteur évoque successivement les problèmes suivants: le leadership de Hruščev et sa légitimation au sein de la direction collégiale (les « 130 jours » de Berija, la définition du programme des réformes, le rôle de Malenkov); puis la liquidation de l'héritage politique stalinien (mise en place d'une nouvelle stratégie en politique extérieure, $\mathrm{XX}^{\mathrm{e}}$ Congrès, création des sovnarkhoz, destitution du "groupe anti-parti», Festival mondial de la jeunesse, conquête de l'espace, disgrâce de Žukov) ; tournants dans la politique intérieure et extérieure (évolution des relations avec les États-Unis et la Chine, mur de Berlin, crise de Cuba, nouvelle orientation vers la « construction du communisme»); aggravation de la crise sociale (déception du peuple et des élites, coup d'État de la nomenklatura). L'histoire de la négociation entre les acteurs politiques - c'est-à-dire les membres de la « direction 
collégiale » - est reconstituée sur la base des archives du parti (RGANI), de la presse, de mémoires, ainsi qu'à l'aide d'entretiens avec certains de ces acteurs (D. S. Poljanskij, P.E. Šelest).

3 L'auteur parvient à certaines conclusions intéressantes dans l'évaluation de la réaction des citoyens aux actions des « réformateurs ». D'après lui, le processus de déstalinisation des esprits a été trop long, et, de fait, n'était pas totalement achevé vers la fin de la période khrouchtchévienne. Le nombre de personnes ayant rejeté la révélation du culte de la personnalité au XXe Congrès aurait excédé celui des "antistalinistes ». Ainsi, la plupart de la population n'aurait pas été prête aux réformes et aux brusques changements du « Dégel ». Selon Aksjutin, la perception des slogans politiques par les Soviétiques était étroitement liée à celle qu'ils avaient de la personnalité de N. S. Hruščev. Sa chute en 1964 est expliquée non seulement par le complot fomenté par son entourage politique, mais aussi et surtout par l'hostilité du peuple à son égard, ce peuple qui n'arrivait pas à lui pardonner d'avoir été privé de son objet d'adoration. La contradiction de la position de Hruščev, qui restait lui-même "staliniste" en quelque sorte, selon ses propres mots, ne jouait pas non plus en sa faveur, en repoussant ceux qui se sentaient « antistalinistes » et croyaient assister à l'émergence d'un nouveau culte de la personnalité.

4 Néanmoins, les résultats de l'enquête révèlent qu'un pourcentage important des enquêtés étaient conscients à l'époque de reproduire les idées de la presse soviétique et n'estimaient pas possible de critiquer l'action du pouvoir. Toutefois, Aksjutin ne commente pas ce phénomène. Il ne propose que des éléments de réponse à la question centrale de savoir par quels mécanismes se forme l'opinion publique dans la société soviétique. Ainsi, à propos des rapports tendus entre le pouvoir central et l'intelligentsia artistique, il affirme que les autorités soviétiques tentaient de manifester leur désir de dialogue avec cette dernière, et ce dans le souci, selon l'auteur, de se concilier le soutien de l'intelligentsia pour influencer la formation de l'opinion publique (p. 389). Et, tout à la fin de l'ouvrage (p. 484), il émet l'idée que l'opinion publique restait formée par l'appareil idéologique et reflétait en gros le discours officiel. Pourtant, Aksjutin ne doute nullement de la présence d'une opinion publique en URSS dans le sens occidental du terme. Pour sortir de la contradiction, il fait une distinction entre opinion publique et " états d'esprit politiques» (političeskie nastroenija), déterminés par "les émotions, les mentalités, les positions idéologiques ", qui se diversifient de plus en plus tout au long de la période et donc ne coïncident pas avec le discours officiel.

5 Croiser les enquêtes effectuées à la fin des années 1990 avec des documents des années 1950-1960 aurait pu constituer un apport supplémentaire à cet ouvrage. La question principale qui se pose quand on utilise comme source des enquêtes d'opinions est la suivante: «Ces opinions sont-elles vraiment contemporaines des événements politiques jugés, ou bien se sont-elles formées a posteriori, après la disparition de l'URSS, sur la vague des révélations de la presse? » Par ailleurs, la comparaison des pourcentages issus des enquêtes avec le nombre de personnes jugées pour propagande contrerévolutionnaire après la mort de Stalin (essentiellement pour avoir exprimé des idées opposées au discours officiel) ${ }^{1}$ pourrait aider à réévaluer l'ampleur des attitudes négatives de la population envers le pouvoir.

6 L'absence d'analyse des résultats de l'enquête se ressent tout au long de l'ouvrage. En général, l'auteur se contente de citer les réponses des enquêtés aux questions posées et de présenter les pourcentages de ceux qui sont pour, contre, sans opinion, ou qui ne désirent 
pas s'exprimer sur le sujet. Il aurait été intéressant de chercher à comprendre la différence entre les résultats obtenus en 1998 et en 1999, années d'enquêtes le plus souvent mentionnées. Le pourcentage des « opposants » au pouvoir varie d'une année à l'autre. On peut supposer que les événements de la fin des années 1990 ont pesé sur les réponses, mettant en doute la fiabilité de ce genre de source.

On aurait pu aussi classer les résultats de l'enquête à partir de différents critères. La critique de l'action du pouvoir est-elle propre à certaines couches sociales, ou à certaines professions, ou aux habitants de certaines régions, par rapport aux autres enquêtés qui disent répéter le discours de l'époque? Cette classification paraît tout à fait envisageable, vu le nombre des enquêtés et leur diversité sociale, professionnelle, culturelle et régionale.

C'est seulement dans la conclusion que l'auteur donne une portée générale à son étude en affirmant qu'au fur et à mesure de l'assouplissement du régime et de l'élargissement du cercle des réformes, les couches moyennes et l'intelligentsia manifestent un intérêt grandissant envers la politique, s'y impliquent, se sentent insatisfaites de l'allure et de l'échelle des transformations et forment ainsi une opposition. Mais, sans preuves documentaires, cette thèse paraît un peu détachée de l'analyse des faits historiques concrets. Ainsi, malgré son ambition, cet ouvrage se place plutôt dans le courant historiographique traditionnel qui s'en tient à une reconstitution événementielle détaillée de l'histoire politique soviétique.

\section{NOTES}

1. V. A. Kozlov et S. V. Mironenko, eds., 58 - 10. Nadzornye proizvodstva Prokuratury SSSR po delam ob antisovetskoj agitacii i propagande. Annotirovannyj katalog. Mart 1953 - 1991 gody, Moscou, Meždunarodnyj fond « Demokratija », 1999. 